\title{
Wiedemann-Rautenstrauch syndrome
}

INSERM

\section{Source}

INSERM. (1999). Orphanet: an online rare disease and orphan drug data base.

Wiedemann-Rautenstrauch syndrome. ORPHA:3455

Wiedemann-Rautenstrauch syndrome is a very rare disorder with features of premature aging recognizable at birth, decreased subcutaneous fat, hypotrichosis, relative macrocephaly and dysmorphism. 